DOI: $10.15690 /$ vramn581

Л.Ю. Милованова, Н.А. Мухин, Л.В. Козловская, Ю.С. Милованов, Г.Г. Киякбаев, И.В. Рогова,

М.В. Лебедева, Т.В. Андросова, С.Ю. Милованова, А.Ю. Гиль, М.В. Таранова

Первый Московский государственный медицинский университет им. И.М. Сеченова, Москва, Российская Федерация

Снижение сывороточного уровня морфогенетического белка Klotho у больных хронической болезнью почек: клиническое значение

\begin{abstract}
Цель исследования: определить значение изменения сывороточного уровня белка Klotho (s-Klotho) y пациентов с хронической болезнью почек (ХБП) 1-5D стадий. Методы. Обследованы 130 больных ХБП 1-5D стадий (67 мужчин и 63 женщины; средний возраст

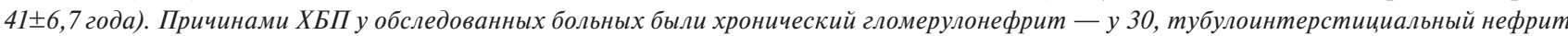
(лекарственной, подагрической этиологии) - у 23, поликистоз почек - у 22, гипертензивный нефросклероз - у 28, сахарный диабет 2-го типа - у 27. У всех больных исходно и через 1 год наблюдения исследованы сывороточные уровни паратиреоидного гормона (ПТГ), кальция, фосфора, белка s-Klotho (методика ELISA). Всем пациентам измеряли уровень артериального давления (АД), в том числе иентрального (аортального), скорость пульсовой волны с помощью аппарата SphygтоСог (Австралия); выполняли эхокардиографию, рентгенографию брюшной аорты в боковой проекции. Результаты. При сравнении уровня s-Кlotho у больных с разными стадиями ХБП оказалось, что по мере снижения скорости клубочковой фильтрации (СКФ) его изменение в сыворотке начинается уже с ЗА стадии ХБП и опережает повышение уровня фосфора и ПТГ, которые отмечены с 4-5-й стадии ХБП. Согласно RОС-анализу, значение s-Кlотһо ниже 387 пг/мл с чувствительностью $80 \%$ и специфичностью 75\% свидетельствовало об увеличении риска кальцификации абдоминальной аорты. Кроме того, выявлена статистически значимая отрицательная взаимосвязь низкого уровня 5 -Кlотһо с ремоделированием сердиа (развитие гипертрофии левого желудочка и кардиомиопатии). При сравнении пациентов с артериальной гипертензией, которые получали антигипертензивную монотерапию, наиболее высокий уровень белка s-Кlotho отмечен у пациентов, у которых целевой уровень АД был достигнут преимущественно с помощью блокаторов рецепторов к ангиотензину II, по сравнению с теми, кто использовал другие группы препаратов ( $<0,01)$ или не достиг целевого уровня АД ( (снижение) по мере прогрессирования ХБП ассоциировано с увеличением степени ремоделирования сердиа и кальцификации сердиа и сосудов и может рассматриваться в качестве раннего самостоятельного маркера поражения сердечно-сосудистой системы при ХБП. Полученные нами предварительные данные о влиянии коррекции АД на уровень $s$-Кlotho свидетельствуют о возможности медикаментозного поддержания сывороточного уровня s-Klotho и требуют дальнейших исследований.

Ключевые слова: хроническая болезнь почек, экстрацеллюлярная форма (s-форма) белка Кlотһо, кальцификация сердиа и сосудов. (Для цитирования: Милованова Л.Ю., Мухин Н.А., Козловская Л.В., Милованов Ю.С., Киякбаев Г.Г., Рогова И.В., Лебедева М.В., Андросова Т.В., Милованова С.Ю., Гиль А.Ю., Таранова М.В. Снижение сывороточного уровня морфогенетического белка Кlоthо у больных хронической болезнью почек: клиническое значение. Вестник РАМН. 2016;71(4):288-296. doi: 10.15690/vramn581)
\end{abstract}

L.Y. Milovanova, N.A. Mukhin, L.V. Kozlovskaya, Y.S. Milovanov, G.G. Kiyakbaev, I.V. Rogova, M.V. Lebedeva, T.V. Androsova, S.Y. Milovanova, A.Y. Gil, M.V. Taranova

I.M. Sechenov First Moscow State Medical University, Moscow, Russian Federation

\title{
Decreased Serum Levels of Klotho Protein in Chronic Kidney Disease Patients: Clinical Imortance
}

Objective: to determine the role of serum Klotho (s-Klotho) protein levels changes in patients with different stages of chronic kidney disease (CKD).

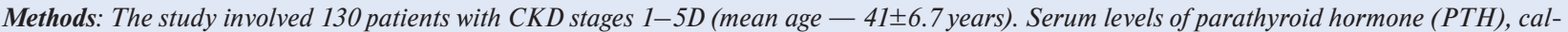
cium, phosphorus and s-Klotho protein (ELISA method) at baseline and after 1 year of follow-up were examined in all the patients so as the blood pressure (BP), including central (aortic), pulse wave velocity - with the help of «Sphygmocor» (Australia), echocardiography, radiography of the abdominal aorta in a lateral projection were also performed. Results: when comparing the s-Klotho levels in patients with different CKD stages, it was found that the level change associated with the reduction of glomerular filtration rate (GFR) ahead of phosphorus and PTH increase in serum, stared at $3 A$ CKD, whereas hyperphosphatemia and PTH increase started at 4-5 CKD stages. According to ROC analysis, decreasing of s-Klotho levels below $387 \mathrm{pg} / \mathrm{ml}$ was indicated a calcification risk of abdominal aorta increased with an $80 \%$ sensitivity and $75 \%$ specificity. In addition, a strong negative relationship of low s-Klotho levels and heart remodeling was found. When comparing the patients with hypertension who were receiving antihypertensive monotherapy, the highest serum levels of Klotho protein were observed in those of them whose target blood pressure level was achieved primarily through Angiotensin II Receptors Blockers (ARB), compared to those who was administered another drug group ( $p<0.01$ ) or has not reached the target blood pressure level $(p=0,008)$. Conclusion: The change of serum Klotho levels (decrease) in CKD progression is associated with the degree (increase) of cardiovascular calcification and remodeling (the development of left ventricular hypertrophy, and cardiomyopathy) and it can be seen as an early independent marker of the cardiovascular system lesions in CKD. Our preliminary data of the effect of blood pressure correction on s-Klotho levels may indicate the possibility of drug maintaining serum Klotho levels and it requires further research. Key words: chronic kidney disease (CKD), soluble Klotho (s-Klotho), cardiovascular calcification.

(For citation: Milovanova LY, Mukhin NA, Kozlovskaya LV, Milovanov YS, Kiyakbaev GG, Rogova IV, Lebedeva MV, Androsova TV, Milovanova SY, Gil AY, Taranova MV. Decreased Serum Levels of Klotho Protein in Chronic Kidney Disease Patients: Clinical Imortance. Annals of the Russian Academy of Medical Sciences. 2016;71(4):288-296. doi: 10.15690/vramn581 ) 


\section{Введение}

Несмотря на достигнутые за последние годы в мировой практике успехи в ведении пациентов с хронической болезнью почек (ХБП), в том числе получающих заместительную почечную терапию, смертность этой категории больных остается по-прежнему высокой. Лидирующую позицию среди причин смерти занимают сердечно-сосудистые осложнения (ССО), риск которых у пациентов с почечной недостаточностью, в том числе у молодых, увеличен в 100 и более раз по сравнению с общей популяцией $[1,2]$.

В генезе развития ССО при ХБП имеют значение многие механизмы, которые в последние годы активно изучаются. Среди них в настоящее время большое внимание уделяется снижению продукции морфогенетического белка Klotho [3-6]. В экспериментальных исследованиях установлено, что дефицит Klotho вызывает развитие множественных системных проявлений (синдром преждевременного старения и др.), обязательным компонентом которых является кальцификация сердца и сосудов [7, 8].

Белок Klotho существует в двух формах - трансмембранной и экстрацеллюлярной (секретируемой). Он продуцируется и секретируется преимущественно клетками проксимальных почечных канальцев. Трансмембранная форма белка Klotho является корецептором для FGF-23 (фосфатурического гормона) и в этом качестве участвует в регуляции обмена фосфора и витамина D. Экстрацеллюлярная часть белка Klotho секретируется в кровоток и функционирует как эндокринный фактор [9]. Предполагают, что циркулирующая форма белка Klotho (s-Klotho) функционирует как гуморальный фактор: снижение уровня s-Klotho в сыворотке крови у мышей было ассоциировано как с прогрессированием тубулоинтерстициального фиброза, так и с развитием кальцификации сердца и сосудов [10].

Замечено, что процессы, сопутствуюшие прогрессированию ХБП, сходны с процессами сосудистого старения организма в целом, но происходят ускоренными темпами, в связи с чем ХБП рассматривают как модель ускоренного сосудистого старения организма $[1,2]$, при этом изучение роли s-Klotho при ХБП может открывать значительные перспективы для торможения процессов кальцификации и снижения сердечно-сосудистого риска в целом.

K настоящему времени большинство исследований роли s-Klotho проведено в эксперименте или на популяции лишь для диализных больных $[5,6]$. У пациентов с додиализными стадиями роль белка s-Klotho изучена значительно хуже.

В то же время понимание ранних механизмов развития ССО у больных ХБП имеет важное значение для разработки новых терапевтических стратегий.

Целью исследования было определить роль экстрацеллюлярной (циркулирующей) формы морфогенетического белка Klotho у пациентов с ХБП 1-5D стадий.

\section{Методы}

\section{Дизайн исследования}

Проведено проспективное когортное исследование.

\section{Критерии соответствия}

Согласно международным критериям, участниками исследования стали мужчины и женщины в возрасте от 18 до 65 лет с ХБП 1-5D стадий. При определении стадии
ХБП пользовались рекомендациями Экспертной группы по оценке качества исходов заболеваний почек Национального почечного фонда (National Kidney Foundation Kidney Disease Outcomes Quality Initiative, NKF KDOQI Guidelines, 2002), при этом скорость клубочковой фильтрации (CKФ) рассчитывали по уравнению CKD-MDRD (Chronic Kidney Desease Modification of Diet in Renal Disease) [2].

Критериями невключения являлись: наличие обострения хронического гломерулонефрита, требующего лечения глюкокортикостероидами и цитостатиками, хронической сердечной недостаточности III-IV функционального класса (по классификации Нью-Йорской ассоциации кардиологов - NYHA), онкологических и системных заболеваний, беременности.

\section{Условия проведения}

Исследование выполнено на базе клиники нефрологии, внутренних и профессиональных болезней им. Е.М. Тареева Первого Московского государственного медицинского университета им. И.М. Сеченова. Необходимое для проведения исследования оборудование было любезно предоставлено указанным центром.

\section{Продолжительность исследования}

Пациенты были прослежены в динамике в течение 1 года (в период с мая 2014 по май 2015 г.).

\section{Описание медицинского вмешательства}

У всех больных уточняли этиологию ХБП, сопутствующую патологию сердечно-сосудистой системы.

Помимо стандартного клинико-лабораторного обследования всем пациентам для решения поставленных задач было проведено определение уровней паратиреоидного гормона (ПТГ), кальция и фосфора в сыворотке крови. Сывороточный уровень белка s-Klotho оценивали иммуноферментным методом (Human alpha-Kl ELISA kit с использованием anti-Klotho антител).

Всем пациентам измеряли уровень артериального давления (АД), в том числе центрального (аортального) с помощью прибора Sphygmocor (Австралия), проводили электрокардиографию (ЭКГ); эхокардиографию (ЭхоКГ) согласно стандартному протоколу [11] с расчетом индекса массы миокарда левого желудочка; рентгенографию брюшной аорты в боковой проекции по методу Каuppila; расчет скорости пульсовой волны с помощью прибора SphygmoCor.

\section{Анализ в подеруппах}

Причиной ХБП у 130 обследованных больных были хронический гломерулонефрит - у 30, тубулоинтерстициальный нефрит (лекарственной, подагрической этиологии) - у 23, поликистоз почек - у 22, гипертензивный нефросклероз - у 28, сахарный диабет 2-го типа - у 27. В исследование вошли 67 мужчин и 63 женщины в возрасте от 20 до 65 лет (средний возраст на момент включения составил $41 \pm 6,7$ года). Больные были разделены на подгруппы, соответствующие стадии ХБП, сопоставимые по полу, возрасту и количеству участников (18-20 человек) на каждой стадии ХБП. Контрольную группу составили 40 здоровых добровольцев, сопоставимых с основной группой наблюдения по возрасту и полу.

Для оценки влияния различных антигипертензивных препаратов на сывороточный уровень белка s-Klotho среди обследованных нами больных были отобраны пациенты с ХБП 1-4-й стадии, имеющие в качестве факторов риска прогрессирования ХБП преимущественно 
повышение уровня АД. Отобранные больные $(\mathrm{n}=76)$ были разделены в соответствии с применяемой для коррекции уровня АД группой антигипертензивных препаратов (ингибиторы ангиотензинпревращающего фермента, блокаторы рецепторов к ангиотензину II, блокаторы кальциевых каналов, бета-блокаторы) на подгруппы, сопоставимые по количеству пациентов, полу, возрасту и стадии ХБП.

\section{Методы регистрации исходов}

Исследование являлось наблюдательным.

Измерение уровней изучаемых показателей в сыворотке крови проводили исходно и через 1 год наблюдения на фоне кардио- и нефропротективной терапии, применяемой в соответствии с рекомендациями экспертов Инициативы по улучшению качества исходов заболеваний почек (Kidney Disease: Improving Global Outcomes, KDIGO, 2009) для каждой стадии ХБП [2].

Помимо стандартных лабораторных показателей, включавших в том числе уровни кальция, фосфора, ПТГ в сыворотке крови, оценивалась динамика среднего сывороточного уровня Klotho в зависимости от стадии ХБП. Кроме того, в каждой группе изучались данные ЭхоКГ, рентгенографии брюшной аорты, скорости пульсовой волны на момент скрининга и в динамике через 1 год. Пациенты проходили амбулаторное лечение в клинике нефрологии, внутренних и профессиональных болезней им. Е.М. Тареева. Случаи госпитализации в нефрологическое отделение фиксировались и тщательно изучались (причина госпитализации, исходный сывороточный уровень s-Klotho и др.). За время наблюдения из 130 пациентов были госпитализированы 48: причиной у всех послужили ССО (преимущественно усугубление артериальной гипертензии, стенокардии, аритмии, в том числе вновь возникшие). Из 48 госпитализированных пациентов за период наблюдения четверо умерли. Причинами смерти были острая сердечная недостаточность на фоне инфаркта (у 1 больного), некупированной пароксизмальной тахиаритмии (у 1), декомпенсированной кардиомиопатии, тяжелой анемии (у 1), острого нарушения мозгового кровообращения (у 1).

\section{Этическая экспертиза}

Все пациенты подписывали добровольное согласие на участие в исследовании. Исследование было одобрено локальным Этическим комитетом Первого МГМУ им. И.М. Сеченова. Все процедуры выполнялись в соответствии с Хельсинкской декларацией 2013 г.

\section{Статистический анализ}

Принципы расчета размера выборки

Размер выборки определялся из расчета минимального статистически достоверного количества пациентов в одной группе наблюдения, соответствующей одной стадии хронической болезни почек (20 человек). В связи с наличием 5 стадий ХБП и стадии диализа минимальный размер выборки был определен 120 пациентов, минимальный размер контрольной группы - 20 человек. Реальный размер выборки после набора пациентов составил 130, контрольной группы - 40 добровольцев, сопоставимых по полу и возрасту с основной группой.

\section{Методы статистического анализа данных}

Статистическую обработку результатов выполняли с использованием программы SPSS for Windows 17, которая включала корреляционный анализ с оценкой коэффициента корреляции (r) по Пирсону для установления взаимосвязи между значениями исходных характеристик; статистический парный t-тест Стьюдента для сравнения статистической значимости разницы средних в подгруппах; метод линейной регрессии с построением диаграмм для определения зависимости одной количественной переменной от другой, а также ROC-анализ (Receiver operating characteristic) для расчета концентрации белка s-Klotho, при которой начинает изменяться кальцификация сердца (оценка по полуколичественной балльной шкале).

\section{Результаты}

\section{Объект исследования}

В исследование было включено 130 пациентов с ХБП $1-5 \mathrm{D}$ стадий (67 мужчин и 63 женщины в возрасте 1865 лет, средний возраст на момент включения составил $41 \pm 6,7$ года).

Все пациенты были распределены на подгруппы согласно стадии ХБП (6 подгрупп) для оценки основных результатов исследования.

Для оценки дополнительных результатов исследования пациенты с 1-4-й стадиями ХБП $(\mathrm{n}=76)$ были разделены на подгруппы (5 подгрупп) в соответствии с применяемым для снижения АД классом антигипертензивных препаратов (1 - антагонисты рецепторов к ангиотензину II, 2 - ингибиторы ангиотензинпревращающего фермента, 3 - антагонисты кальциевых каналов, 4 - бета-блокаторы, 5 - другие).

\section{Основные результаты исследования}

По нашим данным, сывороточная концентрация Klotho различалась среди изученных больных в зависимости от СКФ. Наиболее низкий уровень s-Klotho отмечен у больных на гемодиализе (рис. 1).

При сравнении сывороточного уровня белка s-Klotho у больных с разными стадиями ХБП оказалось, что изменение его концентрации происходит по мере снижения СКФ, начиная уже с 3А стадии ХБП (СКФ 4560 мл/1,73 м² в мин), в то время как гиперфосфатемия и повышение ПТГ - с 4-5-й стадии ХБП (СКФ 1530 мл/1,73 м² в мин; рис. 2).

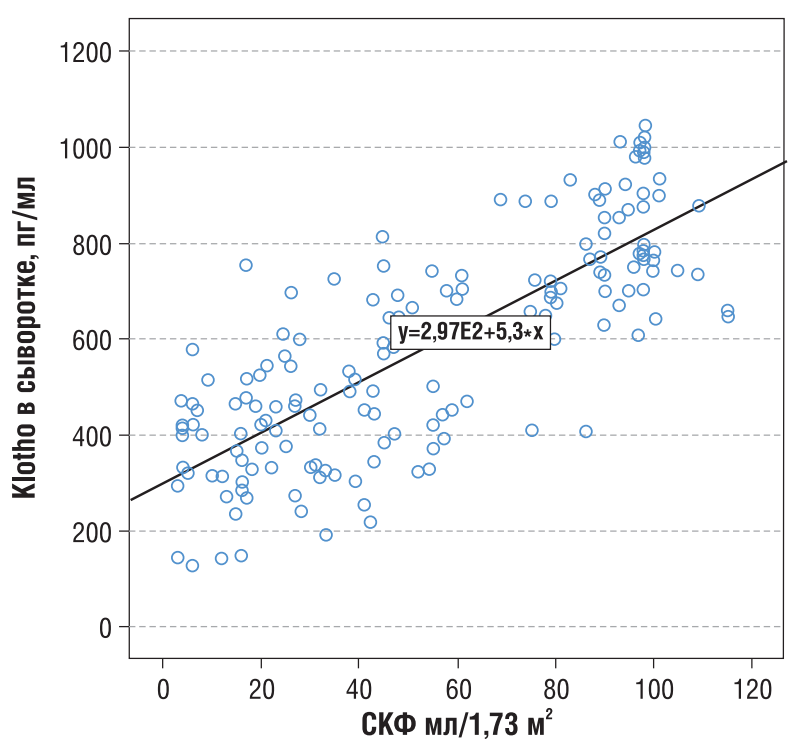

Рис. 1. Прямая зависимость сывороточного уровня s-Klotho от CKФ (по уравнению MDRD)

Примечание. СКФ - скорость клубочковой фильтрации. 


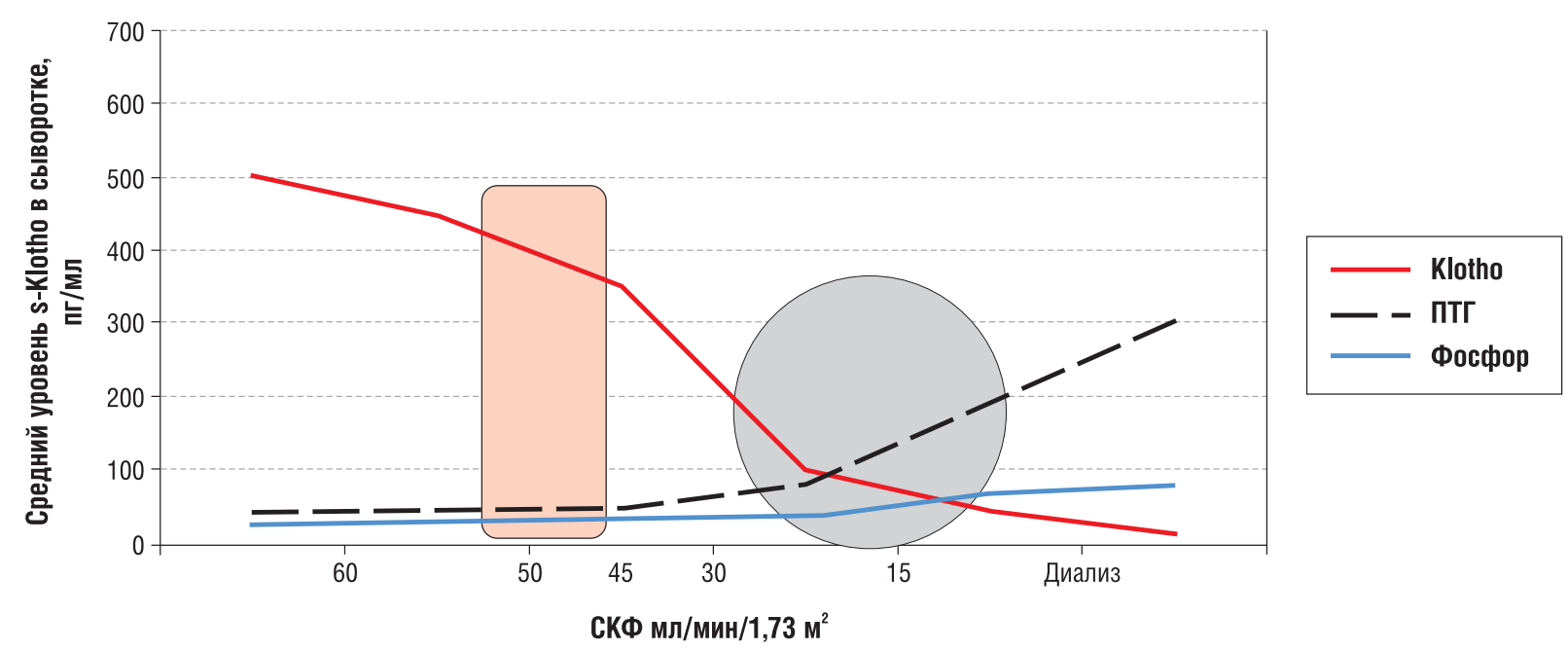

Рис. 2. Динамика сывороточного уровня белка s-Klotho, ПТГ, фосфора у больных хронической болезнью почек в зависимости от скорости клубочковой фильтрации

Примечание. ПТГ — паратиреоидный гормон, СКФ - скорость клубочковой фильтрации. Розовый прямоугольник и серый овал отражают область начала изменения параметров в зависимости от СКФ: Klotho - раньше (диапазон 45-50 мл/мин СКФ), остальные - ПТГ и фосфор - позже (диапазон -15-30 мл/мин СКФ).
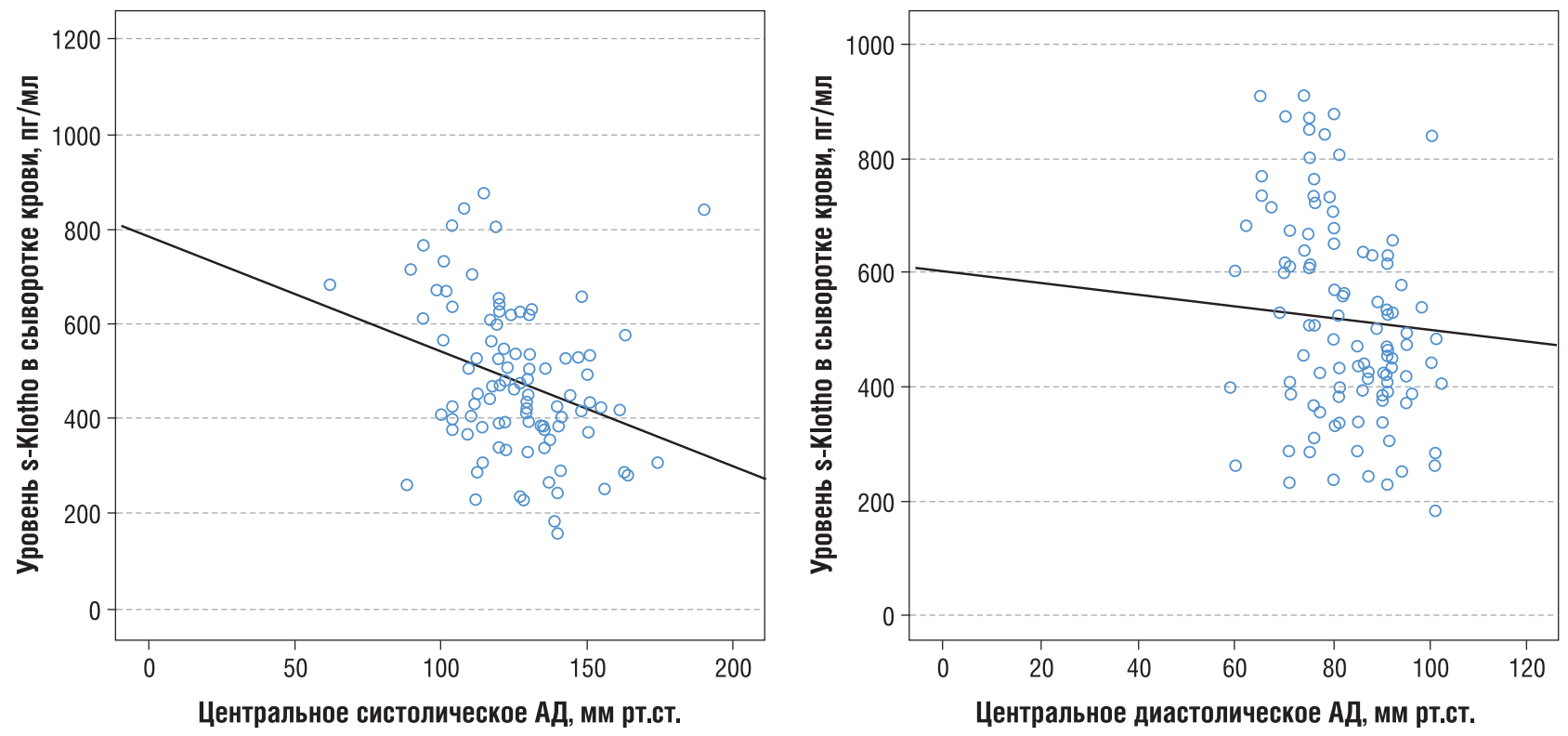

Рис. 3. Взаимосвязь уровня белка s-Klotho с параметрами центрального систолического и диастолического артериального давления (по данным прибора SphygmoCor)

Примечание. АД - артериальное давление.

У 96\% больных, включенных в исследование, на момент начала наблюдения имелась артериальная гипертензия разной степени выраженности. Степень повышения АД (как систолического, так и диастолического) обратно коррелировала с уровнем белка s-Klotho. Обратные корреляции по данным прибора Sphygmocor получены также для уровней белка s-Klotho и центрального систолического и центрального диастолического АД ( $\mathrm{r}=-0,547 ; p<0,01$ и $\mathrm{r}=-0,445 ; p<0,01$ соответственно; рис. 3 ).

Сходный характер взаимосвязи выявлен и для пульсового АД (рис. 4)

Также отмечено, что у пациентов, у которых не удалось достигнуть целевых значений уровня АД, уровень s-Klotho был заметно ниже, а индекс массы миокарда левого желудочка - существенно выше (рис. 5Б), чем у пациентов с достигнутым целевым уровнем АД (рис. 5А)

Нами оценена взаимосвязь изучаемого биомаркера с жесткостью сосудов и выраженностью кальциноза сердца

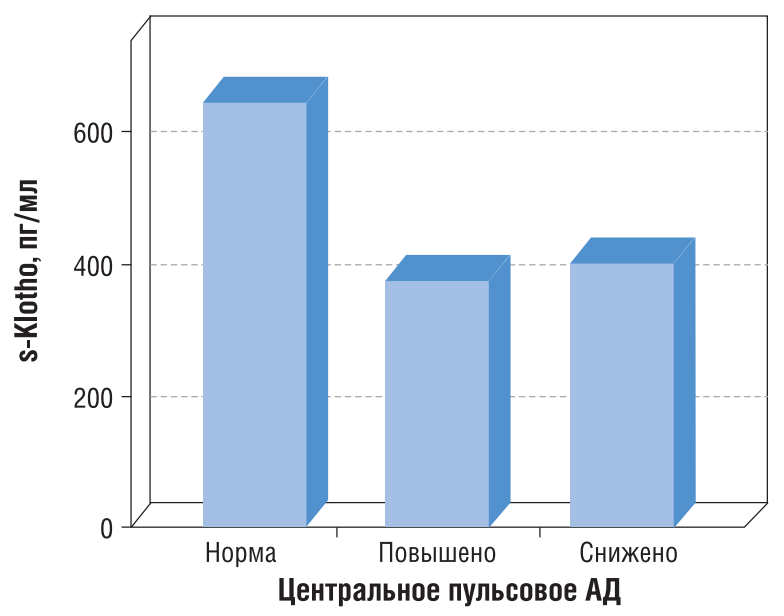

Рис. 4. Взаимосвязь центрального пульсового АД с уровнем s-Klotho в сыворотке крови

Примечание. АД - артериальное давление. 

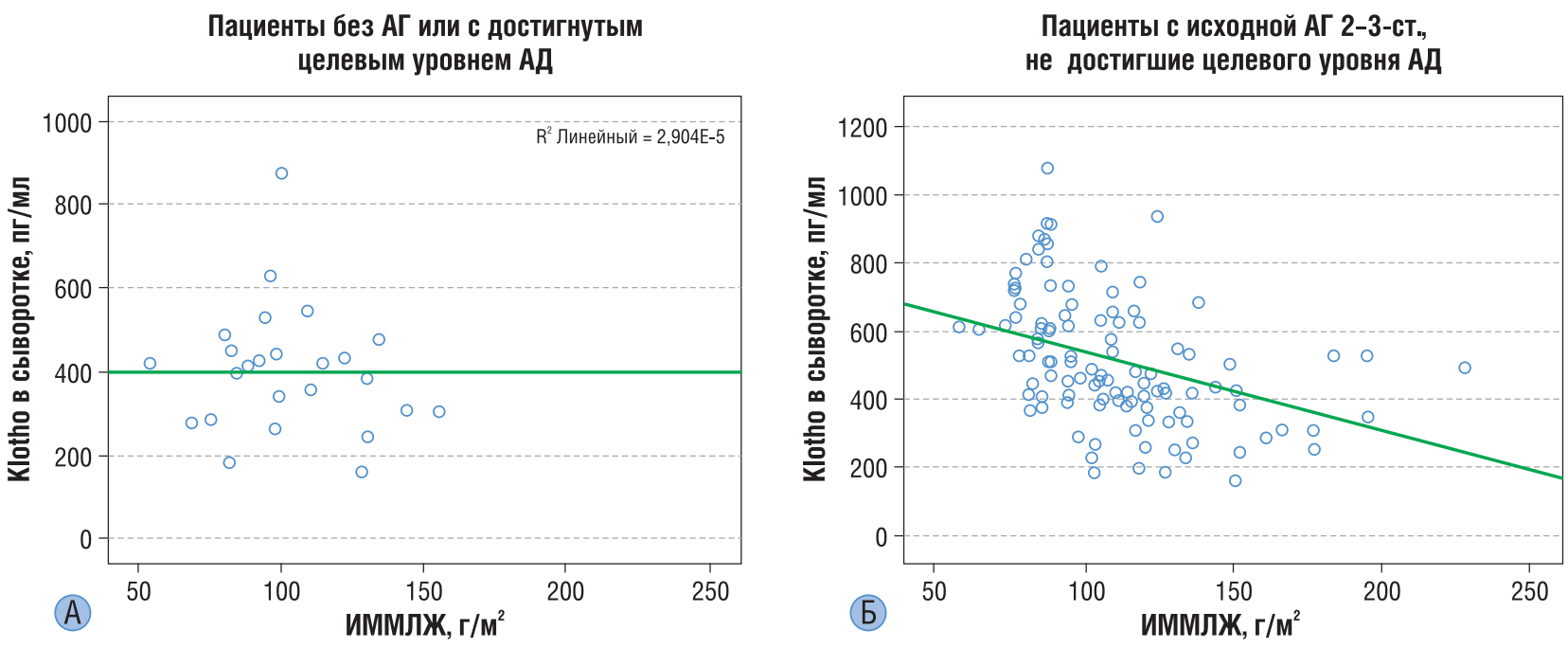

Рис. 5. Сывороточный уровень Klotho и индекс массы миокарда левого желудочка (по данным ЭхоКГ) в зависимости от адекватности коррекции уровня АД

Примечание. ИММЛЖ - индекс массы миокарда левого желудочка, АД - артериальное давление, АГ - артериальная гипертензия.

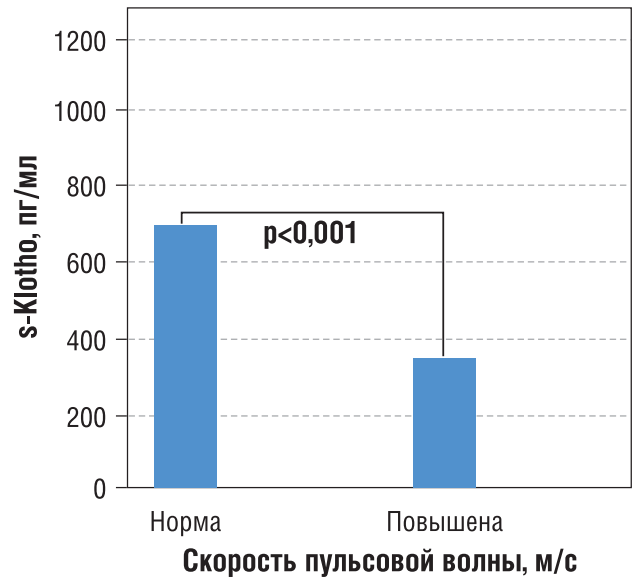

Рис. 6. Скорость пульсовой волны в зависимости от уровня белка s-Klotho у больных хронической болезнью почек

и сосудов. Установлена значимая связь снижения уровня s-Klotho со скоростью пульсовой волны - интегральным показателем жесткости сосудистой стенки (рис. 6).

У больных ХБП мы выявили значительную распространенность кальциноза клапанов сердца (по данным ЭхоКГ) с преимущественным поражением митрального и аортального, причем сочетанная форма поражения обоих клапанов преобладала над изолированной. У этих же больных, по данным ЭхоКГ, установлена значимая связь снижения s-Klotho со степенью увеличения кальциноза сердца при оценке по полуколичественной балльной шкале ( $\mathrm{r}=-0,634 ; p<0,01 ;$ рис. 7$)$.

Сходный характер взаимосвязи выявлен и между степенью кальциноза брюшной аорты (по методу Kauppila) и уровнем белка s-Klotho (рис. 8).

При оценке индекса массы миокарда левого желудочка, по данным ЭхоКГ, выявлена статистически значимая корреляция уровня s-Klotho с параметрами ремоделирования сердца - развитием гипертрофии левого желудочка и дилятационной кардиомиопатии $(\mathrm{r}=-0,564 ; p<0,01$ и $\mathrm{r}=-468 ; p<0,01$ соответственно).

Кроме того, отмечена взаимосвязь низкого уровня sKlotho c наличием ишемической болезни сердца (по клиническим данным; $\mathrm{r}=-0,424, p<0,05)$, распространенного атеросклероза $(\mathrm{r}=-0,652 ; p<0,01)$, нарушениями ритма (по данным ЭКГ) и снижением кровоснабжения субэндокарда по сравнению с нормой (по данным прибора Spygmacor; $\mathrm{r}=0,534, p<0,05)$.

Согласно ROC-анализу, значения уровня s-Klotho ниже 387 пг/мл с чувствительностью $80 \%$ и специфично-

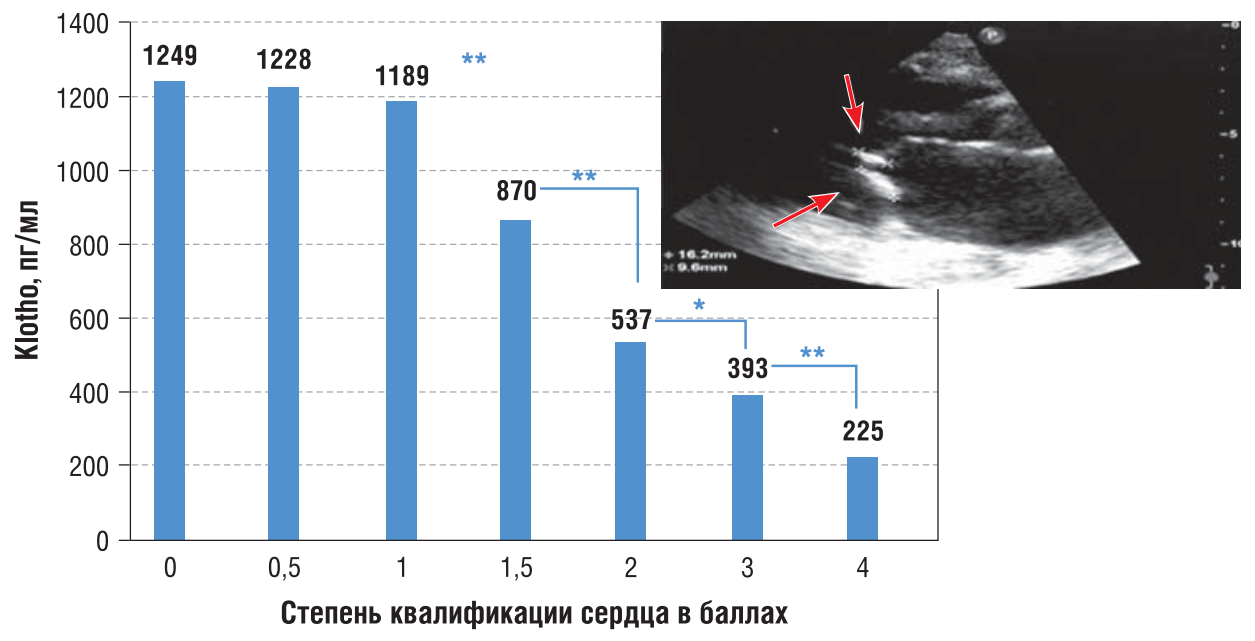

Рис. 7. Взаимосвязь степени кальциноза сердца и уровня s-Klotho у больных хронической болезнью почек

Примечание: * - p<0,05; ** - p<0,01. Стрелками на снимке указан кальциноз клапанов сердца по данным ЭхоКГ. 

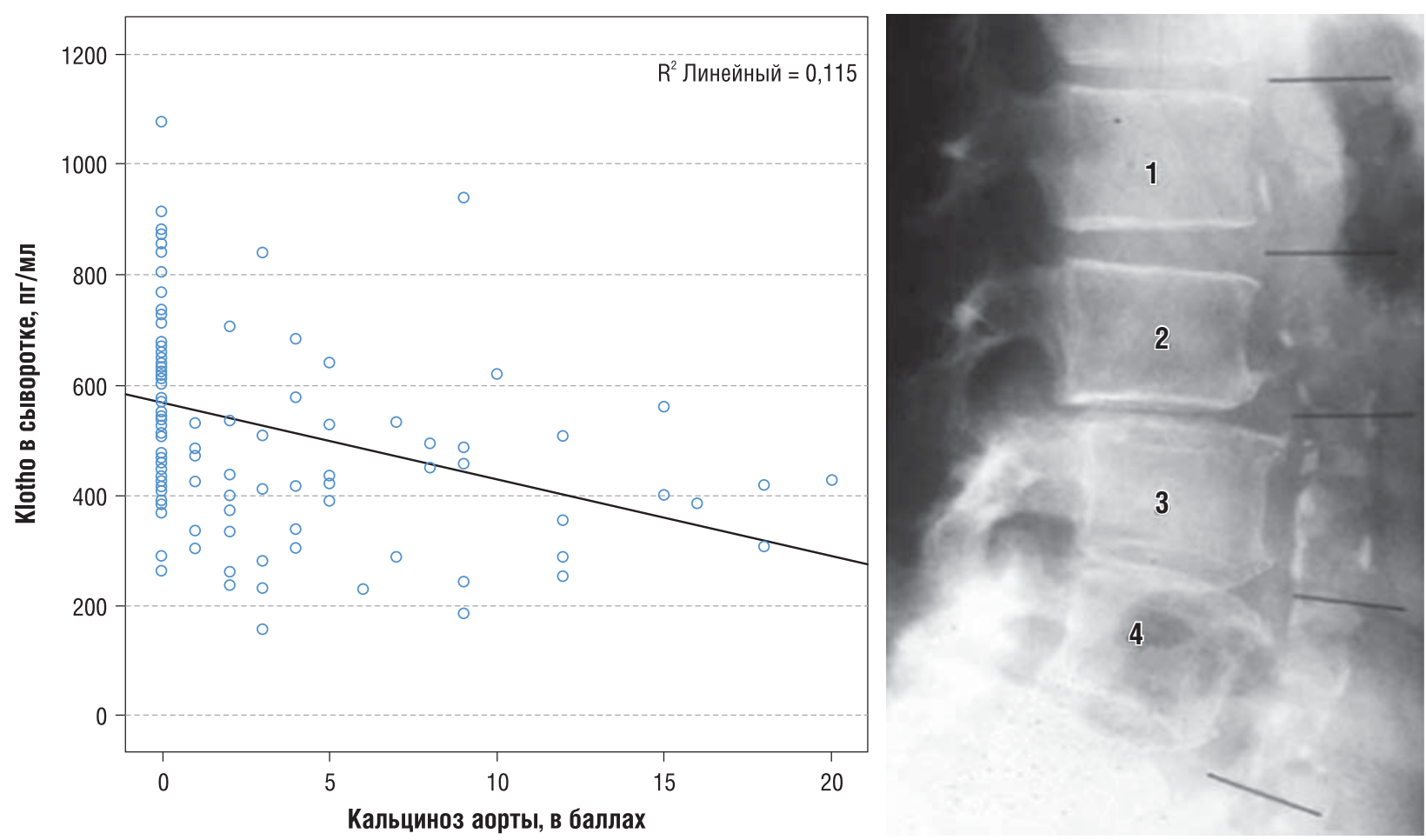

Рис. 8. Взаимосвязь кальциноза брюшной аорты (в баллах, по методу Каuppila) с сывороточным содержанием белка Кlotho у больных хронической болезнью почек

Примечание. Диапазон оценки кальциноза аорты по методу Каupрila - уровень четырех поясничных позвонков (цифры). Напротив каждого позвонка линиями выделены сегменты, по которым оценивается степень кальциноза аорты (передняя ее стенка и задняя) в баллах по каждому сегменту. Баллы суммируются.

стью $75 \%$ свидетельствовали о повышении риска кальцификации сердца (рис. 9).

По данным нашего исследования установлено также, что пациенты с более низким уровнем белка s-Klotho отличались большей потребностью в госпитализациях по поводу ССО и более коротким временем между госпитализациями ( $p<0,01$ и $p<0,05$ соответственно).

\section{Дополнительные результаты исследования}

Принимая во внимание результаты проведенного исследования, мы предприняли попытку ретроспективной оценки влияния получаемой больными антигипертензивной терапии на уровень белка s-Klotho.
Для анализа были отобраны пациенты с ХБП 1-4-й стадии, имеющие среди факторов риска прогрессирования ХБП преимущественно повышение уровня АД. Отобранные группы были сопоставимы по возрасту, полу и стадиям ХБП.

У больных, которым удалось достичь и поддерживать целевой уровень АД (в течение от 6 мес и более) преимущественно с помощью блокаторов рецепторов к ангиотензину II по сравнению с больными с некорригированной артериальной гипертензией и пациентами, получавшими другие группы антигипертензивных препаратов, отмечались более высокие показатели s-Klotho ( $p<0,01$ и $p<0,05$ соответственно) и менее выраженная

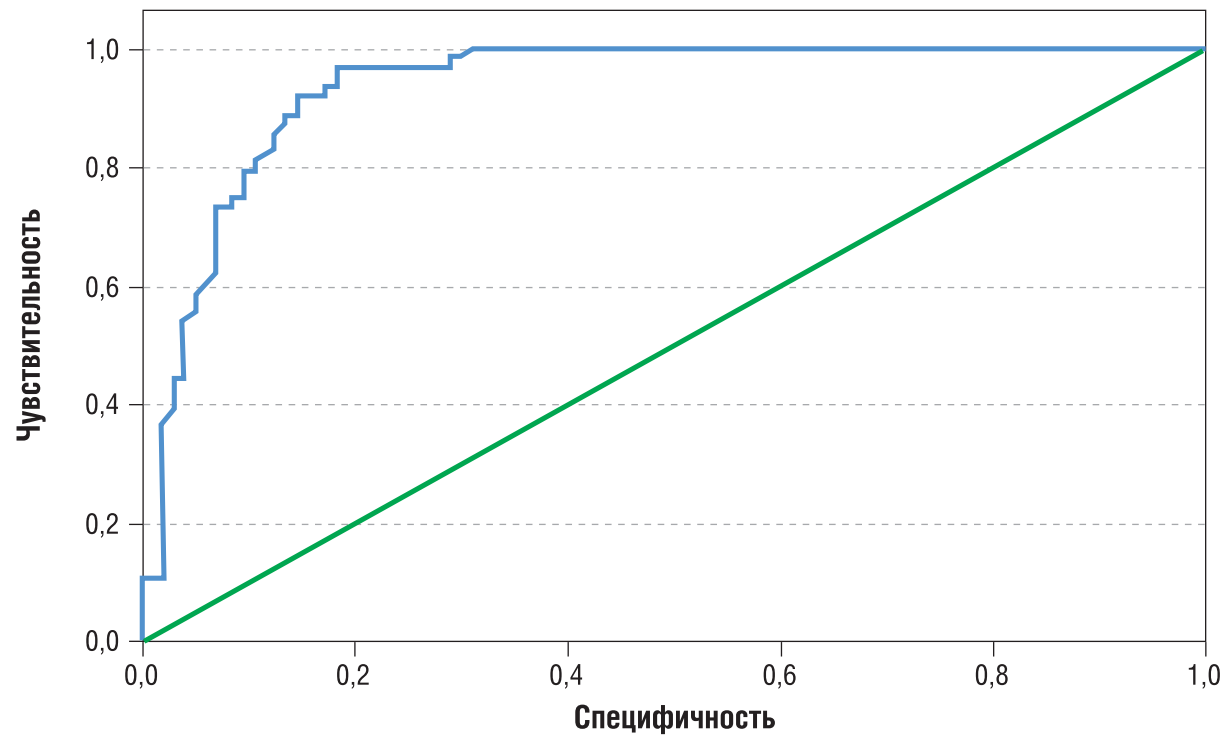

Рис. 9. ROC-анализ влияния низкого уровня s-Klotho на развитие кальцификации брюшной аорты 


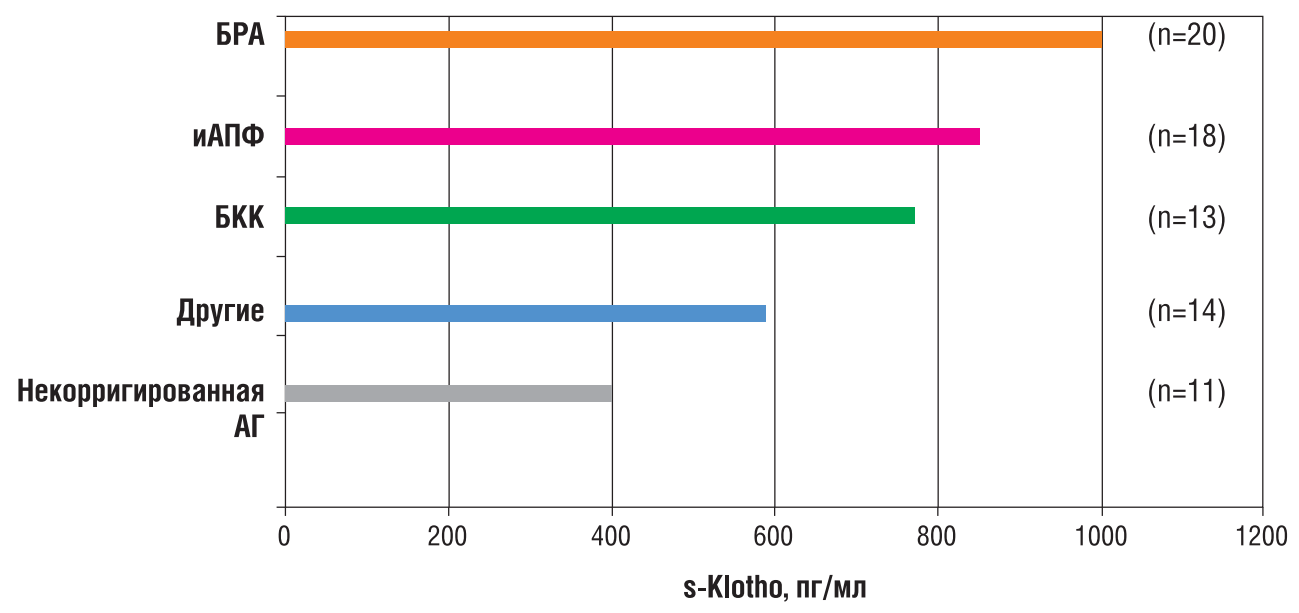

Рис. 10. Влияние различных групп антигипертензивных лекарственных средств (в течение более 6 мес) на уровень белка s-Кlotho у больных хронической болезнью почек с артериальной гипертензией $(\mathrm{n}=76)$

Примечание. АГ - артериальная гипертензия, БРА - блокаторы рецепторов к ангиотензину II, иАПФ - ингибиторы ангиотензинпревращающего фермента, БКК - блокаторы кальциевых каналов.

степень ремоделирования миокарда ( $p<0,05$ и $p<0,05$ соответственно; рис. 10).

У пациентов на гемодиализе, получавших те же препараты, статистически значимых различий по уровню белка s-Klotho и кальцификации сердца и сосудов не выявлено $(p=0,212)$.

\section{Обсуждение}

Наши результаты подтверждают протективную роль белка s-Klotho в отношении развития CCO у пациентов с ХБП. Снижение его уровня ассоциировано с увеличением риска кальцификации сердца и сосудов, развитием гипертрофии левого желудочка, дилятационной кардиомиопатии, госпитализаций по поводу ССО.

Кроме того, дефицит белка s-Klotho является более ранним маркером прогрессирования ХБП и сердечнососудистого риска, чем повышение уровней ПТГ и фосфора.

Установлено, что диффузная артериальная кальцификация начинает развиваться гораздо раньше того, как пациенты достигают диализной стадии, и существенные ее проявления присутствуют более чем у $60 \%$ пациентов, впервые начавших диализ [12]. Кроме того, примерно $40 \%$ пациентов с преддиализной ХБП и более $80 \%$ пациентов, начавших лечение диализом, уже имеют подтвержденную гипертрофию левого желудочка $[13,14]$.

По мере изучения механизмов формирования ССО при ХБП появляется все больше доказательств того, что кальцификация сердца и сосудов уже не представляется процессом, пассивно связанным с преципитацей кальция и фосфора в области эластичной мембраны сосудов. Показано, что под влиянием триггерных факторов, среди которых наряду с изученным ранее повышением уровня фосфора в сыворотке крови обсуждаются и роль нарастающего дефицита продукции белка s-Klotho, и снижение в гладкомышечных клетках сосудов содержания аннексина II (annexin II), и повышение продукции активных радикалов. Это способствует подавлению ангиогенеза и активации Wnt-сигнального пути кальцификации [15-17].

Сосудистая кальцификация развивается в медии без сочетанного утолщения интимы или накопления пенистых клеток, и эти сосудистые изменения, не будучи типичным атеросклерозом, напоминают артериосклероз Менкебер- га - протяженную, диффузную кальцификацию медии, которая помимо ХБП встречается также у людей старшей возрастной группы и у пациентов с диабетической нефропатией $[15,16,18]$. Четко показано, что сосудистая кальцификация у s-Klotho-дефицитных мышей является вторичной по отношению к повышению концентрации в сыворотке крови кальция, фосфора и снижению уровней s-Klotho и витамина D при ХБП [18, 19].

В то же время, по данным литературы, у трансгенных мышей с ХБП повышенная экспрессия белка s-Klotho сочеталась с адекватной фосфатурией, хорошей функциональной способностью почек и существенно меньшей степенью кальцификации сердца и сосудов по сравнению с диким типом мышей с ХБП, имеющих сниженную продукцию экстрацеллюлярной формы Klotho [8].

В проведенном нами исследовании снижение уровня s-Klotho при ХБП сочеталось с падением СКФ, достигая максимальных значений у пациентов, получающих диализ. Дефицит s-Klotho коррелировал с высокой степенью артериальной гипертензии, наличием ишемической болезни сердца, аритмий, кальцификации и ремоделирования сердца и сосудов.

В то же время, по нашим данным, у больных ХБП, которым удалось достичь и поддерживать целевой уровень центрального АД (110-120/70-80 мм рт.ст.) с помощью лекарственных средств преимущественно из группы блокаторов рецепторов к ангиотензину II, уровень s-Klotho оказался статистически значимо выше, чем у тех, кто не достиг целевых значений уровня АД либо получал антигипертензивные препараты других групп ( $p<0,01$ и $p<0,05$ соответственно).

Установлено, что рецепторы ангиотензина II участвуют не только в развитии артериальной гипертензии, но и в сигнальном пути процесса старения организма [18]. Избыточная активация рецепторов ангиотензина II 1-го типа наблюдается при гипертензии, «связанной с возрастом», сахарном диабете, а также ХБП [18]. Мыши с поврежденным геном рецептора 1-го типа ангиотензина II характеризовались большей продолжительностью жизни и более низким уровнем оксидативного стресса, чем дикий тип мышей [20]. Как известно, оксидативный стресс вовлечен в патогенез различных патологических состояний, включая ишемию и воспаление. Установлено, что оксидативный стресс (активация факторов транскрипции FoxO, Forkhead transcription factors) в почечных тубулярных клетках, вызванный ангиотензином II, может вести к 
развитию интерстициального фиброза и снижению продукции белка Klotho [18, 21].

С другой стороны, трансгенная сверхэкспрессия Klotho на модели мышей с гломерулонефритом восстанавливала функции митохондрий и предупреждала повреждение их ДНК в почках. Кроме того, отмечено также торможение ускоренного клеточного старения и апоптоза, ассоциированных с гломерулонефритом, что вело к предотвращению потери почечной функции и улучшению выживаемости мышей [22]. Это наблюдение позволило предположить, что белок s-Klotho может индуцировать резистентность к оксидативному стрессу и «защищать» почечную и другие ткани от повреждения $[23,24]$.

В дальнейшем было обнаружено, что активация FoxO регулируется insulin/IGF-1 сигналом. Ингибиция insulin/ IGF-1 сигнала, индуцированная белком Klotho, ассоциировалась с увеличением резистентности к оксидативному стрессу, что потенциально может вносить вклад в замедление прогрессирования ХБП (тубулоинтерстициального фиброза), а также в уменьшение кальцификации сердца и сосудов [18]. Кроме того, установлено, что внутриклеточный insulin/IGF-1 сигнал является эволюционно сохраненным механизмом, отвечающим за продолжительность жизни [25].

Хотя лежащие в основе сосудистого старения молекулярные механизмы влияния s-Klotho еще не до конца понятны, обратная ассоциация между s-Klotho и ангиотензином II в почках неоднократно подтверждается [23, 26]. В связи с этим логично предположить, что снижение оксидативного стресса с помощью блокаторов рецепторов ангиотензина II может способствовать замедлению снижения продукции s-Klotho [27] и расширить понимание терапевтической эффективности блокаторов ангиотензина II в качестве кардио- и нефропротекторов.

\section{Заключение}

Таким образом, помимо важной роли белка Klotho в минеральном обмене при ХБП становятся все более очевидными его плейотропные эффекты, в первую очередь влияние на развитие $\mathrm{CCO}$, которое начинается уже на ранних стадиях ХБП (3А), что обосновывает возможность практического использования определения уровня белка s-Klotho в качестве раннего маркера сердечно-сосудистого риска у больных ХБП.

Полученные нами предварительные данные о влиянии коррекции артериальной гипертензии на уровень белка sKlotho свидетельствуют о возможности медикаментозной его коррекции и требуют дальнейшего изучения в условиях применения больными ХБП в крупных проспективных исследованиях ингибиторов ангиотензинпревращающего фермента, сартанов, эпоэтина, внутривенного железа, препаратов витамина D. Этот подход может стать началом нового направления кардио- и нефропротективной стратегии.

\section{Источник финансирования}

Работа поддержана Российским научным фондом (грант № 14-15-00947 от 2014 г.). Научно-исследовательская база для выполнения данного проекта была предоставлена вышеупомянутым учреждением.

\section{Конфликт интересов}

Авторы данной статьи подтвердили отсутствие конфликтов интересов, о которых необходимо сообщить.

\section{ЛИТЕРАТУРА}

1. Couser WG, Remuzzi G, Mendis S, Tonelli M. The contribution of chronic kidney disease to the global burden of major noncommunicable diseases. Kidney Int. 2011;80(12):1258-1270. doi: 10.1038/ ki.2011.368.

2. KDIGO clinical practice guideline for the diagnosis, evaluation, prevention, and treatment of Chronic Kidney Disease-Mineral and Bone Disorder (CKD-MBD). Kidney Int Suppl. 2009;(113):S1-130. doi: 10.1038/ki.2009.188.

3. Hruska KA, Seifert M, Sugatani T. Pathophysiology of the chronic kidney disease-mineral bone disorder. Curr Opin Nephrol Hypertens. 2015;24(4):303-309. doi: 10.1097/MNH.0000000000000132.

4. Bae EH. Is Klotho deficiency independently associated with cardiovascular risk in chronic kidney disease? Kidney Res Clin Pract. 2016;35(1):1-2. doi: 10.1016/j.krcp.2016.01.001.

5. Abdallah E, Mosbah O, Khalifa $G$, et al. Assessment of the relationship between serum soluble Klotho and carotid intimamedia thickness and left ventricular dysfunction in hemodialysis patients. Kidney Res Clin Pract. 2016;35(1):42-49. doi: 10.1016/j. krcp.2015.12.006.

6. Oh HJ, Nam BY, Lee MJ, et al. Decreased circulating klotho levels in patients undergoing dialysis and relationship to oxidative stress and inflammation. Perit Dial Int. 2015;35(1):43-51. doi: 10.3747/ pdi.2013.00150.

7. Pavlatou MG, Remaley AT, Gold PW. Klotho: a humeral mediator in CSF and plasma that influences longevity and susceptibility to multiple complex disorders, including depression. Transl Psychiatry. 2016;6(8):e876. doi: 10.1038/tp.2016.135.

8. Hu MC, Kuro-o M, Moe OW. Klotho and chronic kidney disease. Contrib Nephrol. 2013;180:47-63. doi: 10.1159/000346778.
9. Kuro-o M. Klotho in chronic kidney disease what's new? Nephrol Dial Transplant. 2009;24(6):1705-1708. doi: 10.1093/ndt/gfp069.

10. Hu MC, Kuro-o M, Moe O. Renal and extra-renal actions of Klotho. Semin Nephrol. 2013;33(2):118-129. doi: 10.1016/j.semnephrol.2012.12.013.

11. Devereux RB. The value of noninvasive measurements in hypertension. JAMA. 1990;264(21):2798-2799. doi: 10.1001/ jama.264.21.2798

12. Garland JS, Holden RM, Groome PA, et al. Prevalence and associations of coronary artery calcification in patients with stages 3 to 5 CKD without cardiovascular disease. Am J Kidney Dis. 2008;52(5):849-858. doi: 10.1053/j.ajkd.2008.04.012.

13. Middleton RJ, Parfrey PS, Foley RN. Left ventricular hypertrophy in the renal patient. J Am Soc Nephrol. 2001;12(5):1079-1084.

14. Levin A, Singer J, Thompson CR, et al. Prevalent left ventricular hypertrophy in the predialysis population: identifying opportunities for intervention. Am J Kidney Dis. 1996;27(3):347-354. doi: 10.1016/s0272-6386(96)90357-1.

15. Hu MC, Shi M, Zhang J, et al. Klotho deficiency causes vascular calcification in chronic kidney disease. J Am Soc Nephrol. 2011;22(1):124-136. doi: 10.1681/ASN.2009121311.

16. Sharaf El Din UAA, Salem MM, Abdulazim DO. Vascular calcification: When should we interfere in chronic kidney disease patients and how? World J Nephrol. 2016;5(5):398-417. doi: 10.5527/wjn. v5.i5.398.

17. Zhu D, Mackenzie NC, Millan JL, et al. The appearance and modulation of osteocyte marker expression during calcification of vascular smooth muscle cells. PLoS One. 2011;6(5):e19595. doi: 10.1371/journal.pone.0019595. 
18. Yoon HE, Ghee JY, Piao S, et al. Angiotensin II blockade upregulates the expression of Klotho, the anti-ageing gene, in an experimental model of chronic cyclosporine nephropathy. Nephrol Dial Transplant. 2011;26(3):800-813. doi: 10.1093/ndt/ gfq537.

19. Roman-Garcia P, Carrillo-Lopez N, Fernandez-Martin JL, et al. High phosphorus diet induces vascular calcification, a related decrease in bone mass and changes in the aortic gene expression. Bone. 2010;46(1):121-128. doi: 10.1016/j.bone.2009.09.006.

20. Benigni A, Corna D, Zoja C, et al. Disruption of the Ang II type 1 receptor promotes longevity in mice. J Clin Invest. 2009;119(3):524530. doi: 10.1172/JCI36703.

21. Pedraza-Chaverri J, Sanchez-Lozada LG, Osorio-Alonso H, et al. New pathogenic concepts and therapeutic approaches to oxidative stress in chronic kidney disease. Oxid Med Cell Longev. 2016;2016:6043601. doi: 10.1155/2016/6043601.

22. Inselmann G, Hannemann J, Baumann K. Cyclosporine A induced lipid peroxidation and influence on glucose-6-phosphatase in rat hepatic and renal microsomes. Res Commun Chem Pathol Pharmacol. 1990;68(2):189-203.

23. Karalliedde J, Maltese G, Hill B, et al. Effect of renin-angiotensin system blockade on soluble Klotho in patients with type 2 diabetes, systolic hypertension, and albuminuria. Clin J Am Soc Nephrol. 2013;8(11):1899-1905. doi: 10.2215/CJN.02700313.

24. Yamamoto M, Clark JD, Pastor JV, et al. Regulation of oxidative stress by the anti-aging hormone klotho. J Biol Chem. 2005;280(45):38029-38034. doi: 10.1074/jbc.M509039200.

25. Kurosu H, Yamamoto M, Clark JD, et al. Suppression of aging in mice by the hormone Klotho. Science. 2005;309(5742):1829-1833. doi: 10.1126/science.1112766.

26. Kuro-o M. Klotho in health and disease. Curr Opin Nephrol Hypertens. 2012;21(4):362-368. doi: 10.1097/MNH.0b013e32835422ad.

27. Karalliedde J, Smith A, DeAngelis L, et al. Valsartan improves arterial stiffness in type 2 diabetes independently of blood pressure lowering. Hypertension. 2008;51(6):1617-1623. doi: 10.1161/ HYPERTENSIONAHA.108.111674.

\section{КОНТАКТНАЯ ИНФОРМАЦИЯ}

Милованова Людмила Юрьевна, кандидат медицинских наук, доцент кафедры внутренних, профессиональных болезней и пульмонологии МПФ

Адрес: 119435, Москва, ул. Россолимо, д. 11, стр. 4, e-mail: Ludm.milovanova@gmail.com

Мухин Николай Алексеевич, доктор медицинских наук, профессор кафедры внутренних, профессиональных болезней и пульмонологии МПФ, академик РАН, директор клиники нефрологии, внутренних и профессиональных болезней им. Е.М. Тареева

Адрес: 119435, Москва, ул. Россолимо, д. 11, стр. 4, e-mail: Moukhin-nephro@yandex.ru

Козловская Лидия Владимировна, доктор медицинских наук, профессор кафедры внутренних, профессиональных болезней и пульмонологии МПФ

Адрес: 119435, Москва, ул. Россолимо, д. 11, стр. 4

Милованов Юрий Сергеевич, доктор медицинских наук, профессор кафедры нефрологии и гемодиализа Института профессионального образования

Адрес: 119435, Москва, ул. Россолимо, д. 11, стр. 4, e-mail: ymil@mail.ru

Киякбаев Гайрат Гайратович, кандидат медицинских наук, ассистент кафедры внутренних, профессиональных болезней и пульмонологии МПФ

Адрес: 119435, Москва, ул. Россолимо, д. 11, стр. 4, e-mail: gajratki@mail.ru

Рогова Ирина Витальевна, кандидат медицинских наук, ассистент кафедры внутренних, профессиональных болезней и пульмонологии МПФ

Адрес: 119435, Москва, ул. Россолимо, д. 11, стр. 4, e-mail: gajratki@mail.ru

Лебедева Марина Валерьевна, кандидат медицинских наук, доцент кафедры внутренних, профессиональных болезней и пульмонологии МПФ

Адрес: 119435, Москва, ул. Россолимо, д. 11, стр. 4, e-mail: marinaamica@mail.ru

Андросова Татьяна Владиславовна, кандидат медицинских наук, ассистент кафедры внутренних, профессиональных болезней и пульмонологии МПФ

Адрес: 119435, Москва, ул. Россолимо, д. 11, стр. 4, e-mail: androsova@mail.ru

Милованова Светлана Юрвевна, доктор медицинских наук, ведущий научный сотрудник НОКЦ Первый МГМУ им. И.М. Сеченова

Адрес: 119435, Москва, ул. Россолимо, д. 11, стр. 4, e-mail: sveta@mail.ru

Гиль Артём Юрьевич, кандидат медицинских наук, доцент кафедры ВШМ Первый МГМУ им. И.М. Сеченова Адрес: 119435, Москва, ул. Россолимо, д. 11, стр. 4, e-mail: artyom5@mail.ru

Таранова Марина Владимировна, кандидат медицинских наук, доцент кафедры внутренних, профессиональных болезней и пульмонологии МПФ

Адрес: 119435, Москва, ул. Россолимо, д. 11, стр. 4, e-mail: taranova@mail.ru 